\title{
Coronary and Peripheral Vasomotor Responses to Mental Stress
}

Muhammad Hammadah, MD; Jeong Hwan Kim, MD; Ibhar Al Mheid, MD; Ayman Samman Tahhan, MD; Kobina Wilmot, MD; Ronnie Ramadan, MD; Ayman Alkhoder, MD; Mohamed Khayata, MD; Girum Mekonnen, MD; Oleksiy Levantsevych, MD; Yasir Bouchi, MS; Belal Kaseer, MD; Fahad Choudhary, MD; Mohamad M. Gafeer, MD; Frank E. Corrigan III MD; Amit J. Shah, MD; Laura Ward, MPH; Michael Kutner, PhD; J. Douglas Bremner, MD; David S. Sheps, MD; Paolo Raggi, MD; Viola Vaccarino, MD, PhD; Habib Samady, MD; Kreton Mavromatis, MD; Arshed A. Quyyumi, MD

Background-Coronary microvascular dysfunction may contribute to myocardial ischemia during mental stress (MS). However, the role of coronary epicardial and microvascular function in regulating coronary blood flow (CBF) responses during MS remains understudied. We hypothesized that coronary vasomotion during MS is dependent on the coronary microvascular endothelial function and will be reflected in the peripheral microvascular circulation.

Methods and Results - In 38 patients aged $59 \pm 8$ years undergoing coronary angiography, endothelium-dependent and endothelium-independent coronary epicardial and microvascular responses were measured using intracoronary acetylcholine and nitroprusside, respectively, and after MS induced by mental arithmetic testing. Peripheral microvascular tone during MS was measured using peripheral arterial tonometry (Itamar Inc, Caesarea, Israel) as the ratio of digital pulse wave amplitude compared to rest (peripheral arterial tonometry ratio). MS increased the rate-pressure product by $22 \%$ ( $\pm 23 \%$ ) and constricted epicardial coronary arteries by $-5.9 \%(-10.5 \%,-2.6 \%)$ (median [interquartile range]), $P=0.001$, without changing CBF. Acetylcholine increased CBF by $38.5 \%$ (8.1\%, 91.3\%), $P=0.001$, without epicardial coronary diameter change $(0.1 \%[-10.9 \%, 8.2 \%], P=$ not significant). The MS-induced CBF response correlated with endothelium-dependent CBF changes with acetylcholine ( $r=0.38$, $P=0.03)$ but not with the response to nitroprusside. The peripheral arterial tonometry ratio also correlated with the demandadjusted change in CBF during MS ( $r=-0.60, P=0.004)$, indicating similarity between the microcirculatory responses to MS in the coronary and peripheral microcirculation.

Conclusions-The coronary microvascular response to MS is determined by endothelium-dependent, but not endotheliumindependent, coronary microvascular function. Moreover, the coronary microvascular responses to MS are reflected in the peripheral microvascular circulation. (J Am Heart Assoc. 2018;7:e008532. DOI: 10.1161/JAHA.118.008532.)

Key Words: endothelial function • epicardial • flow • mental stress • microvascular • resistance

$\mathrm{M}$ ental stress (MS) has been linked to increased risk of cardiovascular diseases and adverse cardiovascular outcomes. $^{1-3}$ Acute MS results in transient pathological hemodynamic and neuroendocrine activation. ${ }^{4}$ Vasomotor changes in the coronary conductance and resistance vessels modulate coronary blood flow (CBF) during physiologic and psychological stress. ${ }^{5,6}$ For example, vasodilation of the epicardial and coronary microvasculature during maximal exercise can increase CBF by 4- to 5-fold, with the greatest contribution coming from dilation of the resistance or microvessels. ${ }^{7}$ In the normal coronary circulation, acute MS results in dilation of both epicardial arteries and microvessels, increasing CBF to match the increase in demand imposed by the MS-induced increases in blood pressure, heart rate, and

From the Division of Cardiology, Departments of Medicine (M.H., J.H.K., I.A.M., A.S.T., K.W., R.R., A.A., M. Khayata, G.M., O.L., Y.B., B.K., F.C., M.M.G., F.E.C., A.J.S., V.V., H.S., K.M., A.A.Q.) and Psychiatry and Behavioral Sciences (J.D.B.), Emory University School of Medicine, Atlanta, GA; Departments of Epidemiology (A.J.S., L.W., P.R., V.V.) and Biostatistics and Bioinformatics (M. Kutner), Rollins School of Public Health, Emory University, Atlanta, GA; Atlanta VA Medical Center, Decatur, GA (A.J.S., J.D.B., K.M.); Department of Epidemiology, University of Florida College of Medicine, Gainesville, FL (D.S.S.); Mazankowski Alberta Heart Institute, University of Alberta, Edmonton, Alberta, Canada (P.R.).

Accompanying Table S1 and Figures S1 through S5 are available at http://jaha.ahajournals.org/content/7/10/e008532/DC1/embed/inline-supplementarymaterial-1.pdf

Correspondence to: Arshed A. Quyyumi, MD, Division of Cardiology, Department of Medicine, Emory University School of Medicine, 1462 Clifton Road NE, Suite 507, Atlanta, GA 30322. E-mail: aquyyum@emory.edu

Received January 3, 2018; accepted March 28, 2018.

(c) 2018 The Authors. Published on behalf of the American Heart Association, Inc., by Wiley. This is an open access article under the terms of the Creative Commons Attribution-NonCommercial-NoDerivs License, which permits use and distribution in any medium, provided the original work is properly cited, the use is non-commercial and no modifications or adaptations are made. 


\section{Clinical Perspective}

\section{What Is New?}

- This study demonstrates for the first time that microvascular vasomotor changes during mental stress in the digital circulation reflect changes in the coronary circulation.

- Microvascular endothelium-dependent, but not -independent, function predicts coronary microvascular responses during mental stress in patients with coronary artery disease.

\section{What Are the Clinical Implications?}

- Endothelial dysfunction results in impaired vasomotion during mental stress and thus contributes to development of mental stress-induced myocardial ischemia in patients with coronary artery disease.

- Whether improvement of endothelial function will improve coronary vascular responses to mental stress and reduce mental stress-induced myocardial ischemia needs further investigation.

contractility. ${ }^{5,8,9}$ In the presence of coronary artery disease (CAD), epicardial coronary arteries paradoxically constrict, and resistance vessel dilation is markedly impaired, 5,10 resulting in diminished vasodilation that, if severe enough, can lead to myocardial ischemia. ${ }^{5,8-12}$ Other studies, however, have not confirmed this finding., 9,12

The underlying mechanisms for these responses remain understudied. Coronary vasodilation is modulated by both endothelial and nonendothelial mechanisms. Vascular responses to endothelium-dependent agonists such as acetylcholine estimate endothelial function and responses to endothelium-independent agents including sodium nitroprusside reflect smooth muscle and other nonendothelial vasodilatory function; and responses to adenosine largely estimate maximal endothelium-independent microvascular function or flow reserve. One study showed that the magnitude of coronary epicardial endothelial dysfunction significantly correlated with epicardial vasoconstriction during MS. ${ }^{10}$ To our knowledge, no study has assessed the relationship between the epicardial and microvascular responses to MS and coronary vascular endothelium-dependent and -independent function, or with coronary flow reserve. A comprehensive assessment of these responses with MS was 1 goal of our investigation.

Several studies have assessed peripheral vascular changes by measuring digital vasoconstriction in response to MS, by utilizing a noninvasive peripheral arterial tonometry (PAT) device. $^{4,13,14}$ The degree of peripheral microvascular constriction measured with this device has been related to the propensity toward MS-induced myocardial ischemia (MSIMI) in patients with CAD. ${ }^{4,13,14}$ Whether there is any relationship between peripheral and coronary vasomotion during MS has not been previously studied and is a goal of our investigation. $^{4}$

In this study we aimed to examine the relationship between coronary vascular responses to MS and (1) endothelium-dependent epicardial (coronary diameter response) and microvascular function (acetylcholine-mediated CBF and resistance responses), (2) endothelium-independent epicardial and microvascular function (sodium nitroprusside-mediated responses), and (3) endothelium-independent coronary flow reserve (response to adenosine), in patients with stable CAD. We further examined the association between the peripheral and coronary vascular responses during MS. Our hypothesis was that MS-induced coronary vascular responses are associated with endothelium-dependent but not endothelium-independent coronary epicardial and microvascular function. Second, we hypothesized that the coronary microcirculatory responses to MS will correlate with the digital peripheral microvascular reactivity.

\section{Methods}

The data, analytic methods, and study materials will not be made available to other researchers for purpose of reproducing the results or replicating the procedure.

\section{Study Population}

Forty-six people were enrolled from the Mental Stress Ischemia Prognosis Study, ${ }^{15}$ a prospective study that recruited patients with stable CAD between June 2011 and August 2014 at Emory University-affiliated hospitals. Presence of CAD was defined by an abnormal coronary angiogram demonstrating angiographic evidence of atherosclerosis with at least luminal irregularities. Patients with an acute coronary syndrome or with decompensated heart failure during the previous 2 months, end-stage renal disease, or unstable psychiatric conditions were excluded. Clinical information including previous CAD events, CAD risk factors, coronary angiography results, and current medications were documented using standardized questionnaires and chart reviews. Patients were tested in the morning after a 12-hour fast. Antianginal medications ( $\beta$-blockers, calcium-channel blockers, and long-acting nitrates), xanthine derivatives, and caffeine-containing products were withheld for 24 hours before stress testing. Sedation was not given before catheterization in order to exclude the potential effects of these medications on reactivity during MS testing. The research protocol was approved by the Institutional Review Board, and all participants provided informed consent. 


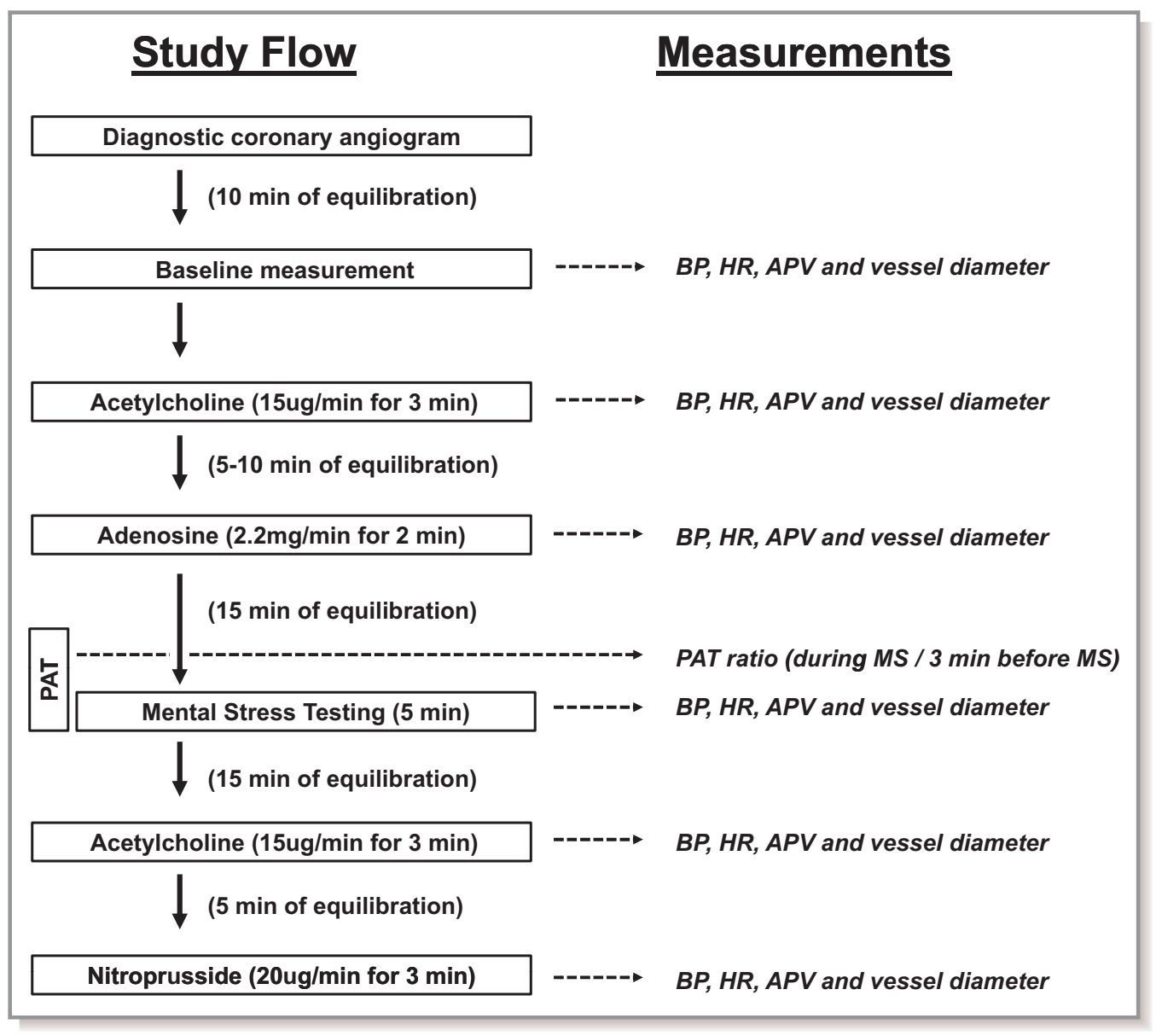

Figure 1. Schematic flowchart of the study protocol and respective measurements. APV indicates average peak velocity; BP, blood pressure; HR, heart rate; MS, mental stress test; PAT, peripheral arterial tonometry.

\section{Cardiac Catheterization}

After insertion of a $7 F$ femoral vascular sheath under local anesthesia and administration of $5000 \mathrm{U}$ of heparin, routine coronary angiography was performed. Patients were not premedicated beforehand with analgesics or sedatives to avoid the effects of these medications on the responses to MS. All measurements were made in unobstructed coronary arteries ( $<20 \%$ stenosis). A 0.014-inch Doppler wire (Flowire, Volcano Corp, Rancho Cordova, CA) was advanced into a nondiseased segment of either the left anterior descending or the circumflex coronary artery through a $7 \mathrm{~F}$ guide and a $3 \mathrm{~F}$ infusion catheter and placed in a straight unoverlapped segment of the epicardial coronary artery without any side branches, which allowed measurement of a stable flowvelocity signal.

Dextrose $5 \%$ was continuously infused through the infusion catheter at a rate of $1 \mathrm{~mL} / \mathrm{min}$. The coronary diameter for calculating CBF was measured in a segment 0.25 to $0.5 \mathrm{~cm}$ beyond the tip of the Doppler wire. CBF $(\mathrm{mL} / \mathrm{min})$ was estimated as $\pi \times$ average peak velocity $(\mathrm{cm} / \mathrm{s}) \times 0.125 \times$ vessel diameter $(\mathrm{mm})$. Coronary vascular resistance (CVR) was calculated as mean arterial pressure $\div \mathrm{CBF}$. To measure epicardial changes during the drug infusions and MS, coronary diameter was also measured in a long $(>1 \mathrm{~cm})$ distal segment of the study coronary artery where the effects of the infused drugs would be evident. Coronary artery diameter changes were measured off-line in the Emory cardiovascular imaging and biomechanical core laboratory using a computerized edge-detection system (PIE Medical Imaging, Maastricht, The Netherlands) by investigators blinded to the patients' demographic and clinical data. ${ }^{16}$ Rate-pressure product was calculated as mean arterial blood pressure $\times$ heart rate.

\section{Study Protocol}

After completion of the diagnostic coronary angiogram and placement of the Doppler Flowire, there was a 10-minute resting period before measurement of resting blood pressure, heart rate, and average peak velocity and performance of a coronary angiogram (Figure 1, Figures S1 and S2). This was followed by measurement of endothelium-dependent 
vasodilation during infusion of intracoronary acetylcholine at a rate of $15 \mu \mathrm{g} / \mathrm{min}$ for 3 minutes to obtain an estimated $10^{-6} \mathrm{~mol} / \mathrm{L}$ intracoronary concentration $(\mathrm{n}=36)$. After a 5 - to 10-minute period to allow for equilibration, coronary flow reserve was measured after a 2-minute infusion of intracoronary adenosine at $2.2 \mathrm{mg} / \mathrm{min}(\mathrm{n}=31)$. After a 15-minute period to allow for equilibration, patients underwent mental arithmetic stress testing $(n=38)$. At the end of 5 minutes of MS testing, the aforementioned measurements were repeated. Fifteen minutes after completion of the MS test, endothelium-dependent vasodilation was remeasured with repeat infusion of intracoronary acetylcholine followed by measurement of endothelium-independent function after infusion of sodium nitroprusside at $20 \mu \mathrm{g} / \mathrm{min}$ for 3 minutes $(n=24)$. Coronary flow and diameter measurements were repeated at the end of each intervention.

\section{Digital Blood Flow Measurement Using Finger Plethysmography}

During the aforementioned study, digital pulse wave amplitude was continuously measured at rest and during MS using PAT (Itamar Medical, Caesarea, Israel) as previously described. ${ }^{13,14}$ Analyzable data free of artifact were available in 24 patients. Briefly, the device, which uses a modified form of plethysmography, was applied to the index finger on the side opposite to the operator. Registered pressure changes were fed into a personal computer where the signal was filtered, amplified, stored, and analyzed in an operatorindependent manner. The baseline pulse wave amplitude was determined by averaging the last 3 minutes of recording that preceded MS testing. The amplitude during MS was determined as the lowest pulse wave amplitude during the arithmetic test. The PAT ratio was calculated as the ratio of the minimum pulse wave amplitude during MS to the baseline, with a ratio $<1$ signifying a vasoconstrictive response. ${ }^{4}$

\section{Statistical Analysis}

Baseline data are reported as mean \pm SD, median (interquartile range), or percentage. Linear regression with repeated measures was employed to test the change in coronary epicardial diameter, $\mathrm{CBF}$, and CVR with each intervention. The median percentage changes are reported with $95 \%$ confidence intervals, which were computed based on order statistics using an incomplete $\beta$ distribution. The Spearman rank correlation was utilized to test associations between the responses during MS and during coronary and peripheral vascular testing. Patients were grouped based on their CBF responses to acetylcholine and nitroprusside using median cutoff values and using a cutoff of 2.5 for coronary flow reserve. ${ }^{17}$ The Mann-Whitney $U$ test was used to test differences between groups in response to MS. Statistical analyses were conducted using SPSS (V 23.0, IBM Corp, Armonk, NY).

\section{Results}

Of the 46 enrolled subjects, 8 patients could not complete the study either for symptomatic reasons or because the CAD was not suitable for insertion of the Flowire and administration of acetylcholine. Thus, 38 subjects, mean age $59 \pm 8$ years, were included in the analysis (Table 1 ).

\section{Coronary Vascular Responses During MS}

MS testing, performed after 15 minutes of equilibration following preceding intracoronary vasomotor challenges, resulted in a significant increase in heart rate (mean \pm SD) (18 \pm 17 beats/min), mean arterial pressure $(14 \pm 11 \mathrm{~mm} \mathrm{Hg})$, and rate-pressure product $(22 \% \pm 23 \%), P<0.001$ for all (Figure 2, Table S1). Overall, there was significant epicardial coronary arterial constriction (median interquartile range $-5.9 \%[-10.5,-2.6] ; P=0.001$ ) during MS, but the responses were heterogeneous; 8 patients had epicardial vasodilation, whereas 30 had constriction during MS (Figure 2, Table S1, Figure S3). Overall, there was no change in the CBF $-2.6 \%$ $(-13.3 \%, 15.7 \%)$ or CVR $12.0 \%(-9.0 \%, 18.6 \%)$, but the responses were heterogeneous (Figure 2, Table S1, Figure S3).

\section{Endothelium-Dependent Function and Response to MS}

Acetylcholine $\left(10^{-6} \mathrm{~mol} / \mathrm{L}\right)$ infusion, performed after the baseline measurements and before any other pharmacologic testing, caused a significant increase in CBF $(38.5 \%$ [8.1\%, 91.3\%], $P=0.001)$ and decrease in CVR $(-29.1 \%$ [ $-49.0 \%$, $-3.4 \%$ ], $P=0.001$ ), but no overall change in coronary epicardial diameter $(0.1 \%[-10.9 \%, 8.2 \%], \quad P=$ not significant $)$ (Table S1). The responses were heterogeneous (Figures S4A and S5A).

There was a significant correlation between the microvascular vasodilator responses, measured as changes in CBF during $M S$ and the $\mathrm{CBF}$ changes with the endotheliumdependent dilator acetylcholine $(r=0.38, P=0.03)$ (Figure 3A). The correlation between coronary epicardial diameter changes during MS and during acetylcholine infusion was not significant $(r=0.15, P=0.40)$ (Figure 3B). However, all patients who had vasoconstriction in response to acetylcholine had vasoconstriction during MS, whereas the response in those who dilated during acetylcholine infusion was more heterogeneous (Figure 3B). Last, the correlation between the CVR changes during MS and with acetylcholine did not reach statistical significance $(r=0.26, P=0.17)$. 
Table 1. Patient Characteristics

\begin{tabular}{|c|c|}
\hline & $\begin{array}{l}\text { Mean (SD), } \\
\text { Median [IQR], or \% }\end{array}$ \\
\hline \multicolumn{2}{|l|}{ Clinical variables } \\
\hline Number & 38 \\
\hline Age, y & $59 \pm 8$ \\
\hline Male, \% & 84 \\
\hline Black, \% & 49 \\
\hline Body mass index, $\mathrm{kg} / \mathrm{m}^{2}$ & $30 \pm 7$ \\
\hline Diabetes mellitus, $\%$ & 30 \\
\hline Hypertension, \% & 71 \\
\hline Hyperlipidemia, \% & 81 \\
\hline Ever smoking, \% & 68 \\
\hline Myocardial infarction, \% & 14 \\
\hline Ejection fraction, $\%$ & $57 \pm 10$ \\
\hline \multicolumn{2}{|l|}{ Previous history } \\
\hline Percutaneous coronary intervention, \% & 19 \\
\hline Heart failure, $\%$ & 13 \\
\hline Depression, \% & 19 \\
\hline PTSD, \% & 5 \\
\hline \multicolumn{2}{|l|}{ Medications } \\
\hline Aspirin, \% & 65 \\
\hline Clopidogrel, \% & 16 \\
\hline Statins, $\%$ & 61 \\
\hline$\beta$-Blockers, \% & 45 \\
\hline ACE inhibitors, \% & 30 \\
\hline \multicolumn{2}{|l|}{ Resting hemodynamics } \\
\hline Heart rate, bpm & $77 \pm 12$ \\
\hline Mean arterial blood pressure, $\mathrm{mm} \mathrm{Hg}$ & $112 \pm 15$ \\
\hline RPP, mm Hg.bpm & $7568 \pm 1892$ \\
\hline \multicolumn{2}{|l|}{ Cardiac catheterization results } \\
\hline \multicolumn{2}{|l|}{ Primary diagnosis of diagnostic angiogram } \\
\hline Obstructive CAD, \% & 26 \\
\hline Nonobstructive CAD, \% & 71 \\
\hline Vasospastic angina, $\%$ & 3 \\
\hline Gensini score & $7.0[2.5,15.5]$ \\
\hline Percentage stenosis of the study vessel & $10 \%[10 \%, 20 \%]$ \\
\hline
\end{tabular}

ACE indicates angiotensin-converting enzyme; bpm, beats per minute; CAD, coronary artery disease; IQR, interquartile range; PTSD, posttraumatic stress disorder; RPP, ratepressure product.

We grouped patients based on their coronary microvascular responses to acetylcholine using a median cutoff of CBF response into those with "less healthy" endothelial function (<median response) and those with "healthier" endothelium ( $\geq$ median response). In patients with $<$ median CBF response

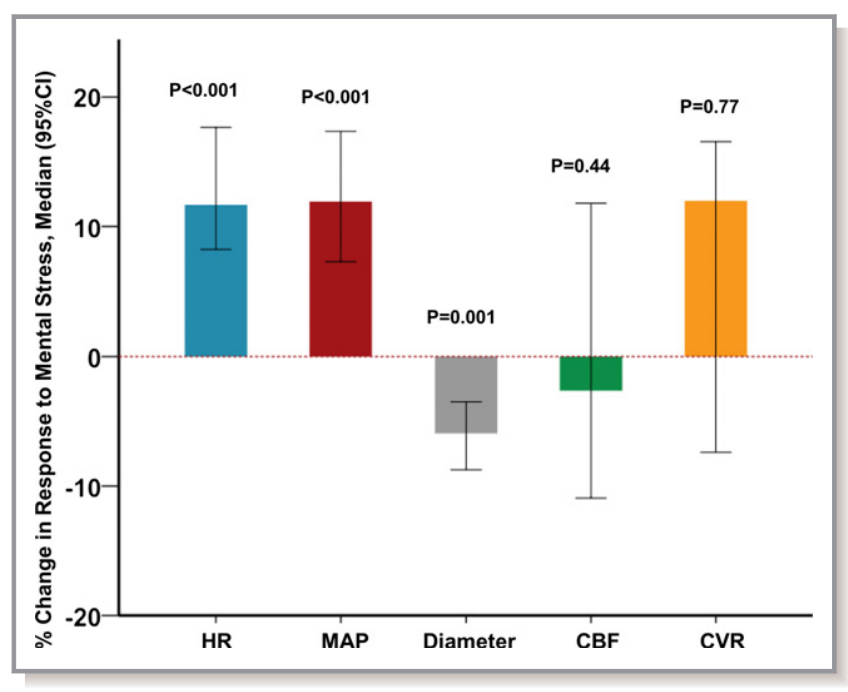

Figure 2. Hemodynamic and coronary vascular responses during mental stress (MS). Bars and error bars represent the median change and $95 \%$ confidence interval, respectively. CBF indicates coronary blood flow; $\mathrm{Cl}$, confidence interval; CVR, coronary vascular resistance; HR, heart rate; MAP, mean arterial pressure.

to acetylcholine, the respective responses during MS were significantly lower than those in subjects with healthier endothelial function ( $>$ median response to acetylcholine) (Figure 4A). However, there were no differences between the epicardial responses to acetylcholine and the epicardial responses to MS.

We also compared the coronary vascular responses to acetylcholine in 20 subjects before and 15 minutes after MS. There were no differences between the epicardial and microvascular responses before and after MS testing; postMS, CBF +45.3\% (16.7\%, 150.4\%), CVR -34.9\% (-56.6\%, $-15.1 \%)$, and epicardial coronary changes $+1.4 \%(-7.4 \%$, $7.6 \%)$ were similar to pre-MS testing values (Table S1).

\section{Endothelium-Independent Function and Response to MS}

Sodium nitroprusside administration, following post-MS acetylcholine challenge, dilated the coronary epicardial arteries $(11.9 \%$ [7.8\%, 22.3\%], $P<0.001)$ and microcirculation (CBF increased $97.3 \%$ [58.2\%, 147.4\%] and CVR decreased $-55.1 \%$ [-67.2\%, $-47.7 \%$, both $P<0.001$ ) (Table S1, Figures S4B and $\mathrm{S} 5 \mathrm{~B})$. There was no correlation between the coronary flow or diameter responses to nitroprusside and the responses to MS (Spearman rank correlation of $0.07, P=0.74)$. We then grouped patients based on their microvascular response to nitroprusside into those with high versus low response using a median cutoff. There was also no significant difference in MSinduced change in CBF or CVR between those with high response versus low response to sodium nitroprusside, respectively (Figure 4B). 


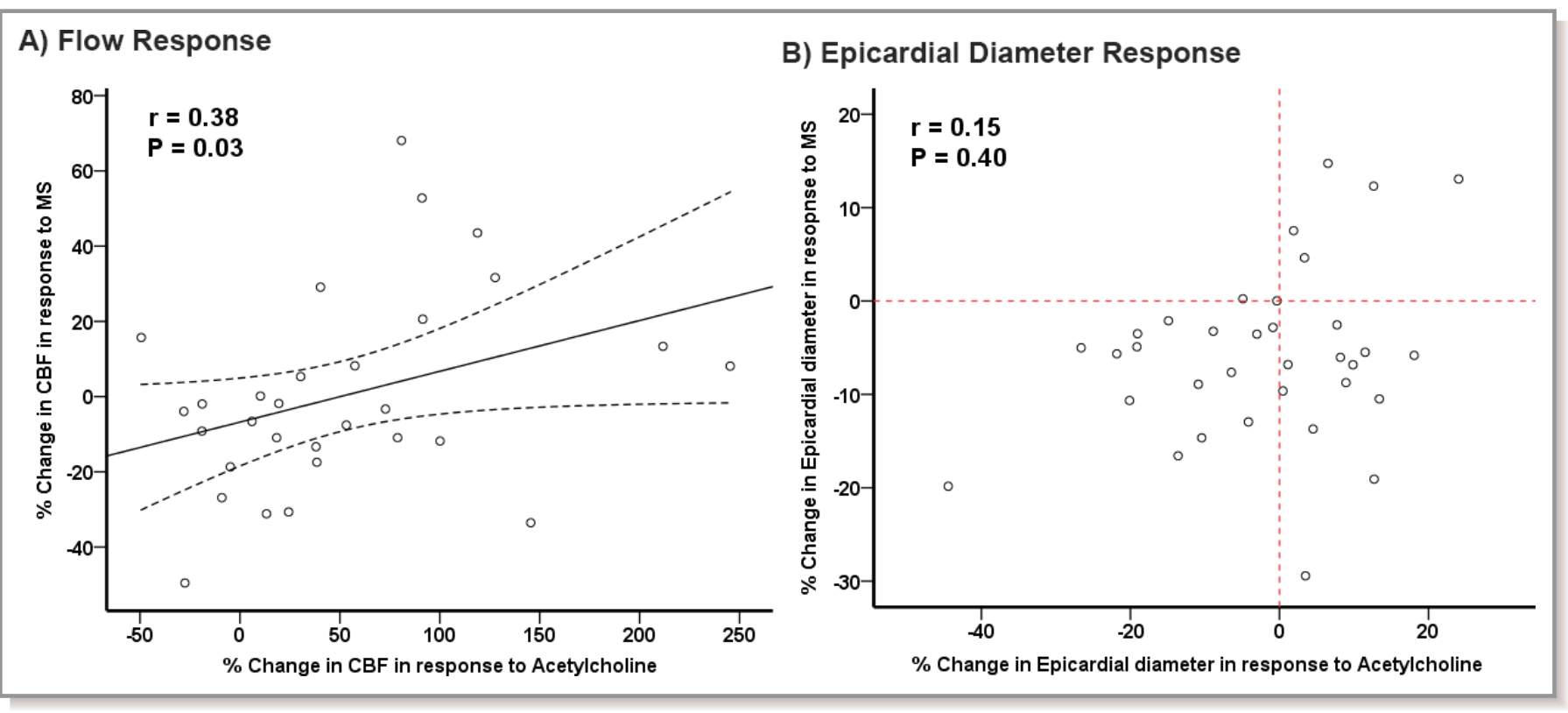

Figure 3. Relationship between coronary blood flow (CBF) and epicardial responses during mental stress (MS) and acetylcholine infusion. $r$ values are Spearman correlation coefficients. A, The solid line represents the line of best fit, and the dashed lines represent $95 \%$ confidence interval. B, The vertical and the horizontal reference lines (dashed) represent no change in epicardial diameter in response to acetylcholine and MS, respectively.

\section{Coronary Flow Reserve and Response to MS}

Intracoronary adenosine, infused after the acetylcholine challenge, significantly increased CBF $(244 \%[166 \%, 398 \%])$ and decreased CVR $(-71.6 \%[-79.1 \%,-58.8 \%]), P<0.001$ for both (Table S1, Figures S4C and S5C). There was no statistically significant correlation between the changes in CBF and CVR with adenosine and MS-induced vasodilation ( $r=-0.10, P=0.6)$. In the 16 patients with normal coronary flow reserve $>2.5$ compared to 15 with coronary flow reserve $<2.5$, there was no difference in the coronary vasomotor responses during MS, (Figure 4C).

\section{Relationship Between Coronary and Peripheral Responses to MS}

MS testing resulted in significant peripheral vasoconstriction; the PAT ratio was $0.76 \pm 0.17 \quad(<1$ indicates digital microvascular constriction). There was a strong inverse correlation ( $r=-0.60, P=0.004$ ) between the PAT ratio and the demand-adjusted coronary microvascular vasodilation, measured as the ratio of rate-pressure product to $\mathrm{CBF}$ (Table 2). Thus, subjects with reduced demand-adjusted coronary vasodilation during MS also had reduced

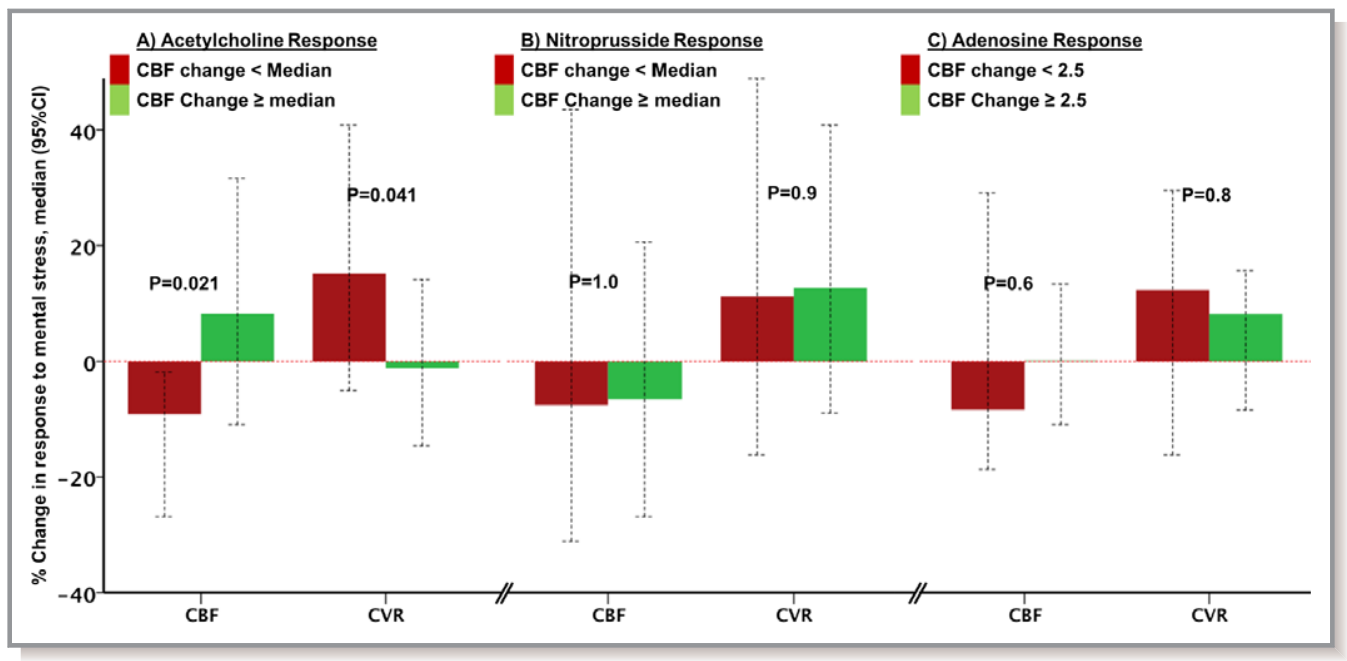

Figure 4. Relationship between coronary microvascular responses during mental stress and during (A) acetylcholine, (B) sodium nitroprusside, and (C) adenosine infusions. Subjects divided by median CBF responses. Bars and error bars represent the median change and $95 \% \mathrm{Cl}$, respectively. CBF indicates coronary blood flow; $\mathrm{Cl}$, confidence interval; CVR, coronary vascular resistance. 
Table 2. Relationship Between Peripheral Microvascular Responses During MS Measured as the PAT Ratio and Coronary Vasomotor Responses During MS

\begin{tabular}{|l|l|l|}
\hline Change With Mental Stress & Spearman Rank Correlation & $P$ Value \\
\hline Epicardial diameter & 0.28 & 0.18 \\
\hline CBF & 0.29 & 0.20 \\
\hline CVR & -0.36 & 0.11 \\
\hline RPP/CBF & -0.60 & $0.004^{*}$ \\
\hline
\end{tabular}

CBF indicates coronary blood flow; CVR, coronary vascular resistance; MS, mental stress; PAT, peripheral arterial tonometry; RPP, rate pressure response. *Statistically significant P-value.

peripheral digital microvascular vasodilation (PAT ratio), and vice versa (Figure 5). No significant correlations were observed between the PAT ratio during MS and MS-induced changes in the coronary epicardial diameter, CBF, or CVR (Table 2).

\section{Discussion}

Our findings demonstrate that in patients with CAD, there is a significant relationship between coronary microvascular responses to MS, measured as changes in CBF and CVR, and the underlying coronary microvascular endotheliumdependent, but not endothelium-independent function. Thus, patients with worse coronary microvascular endothelial

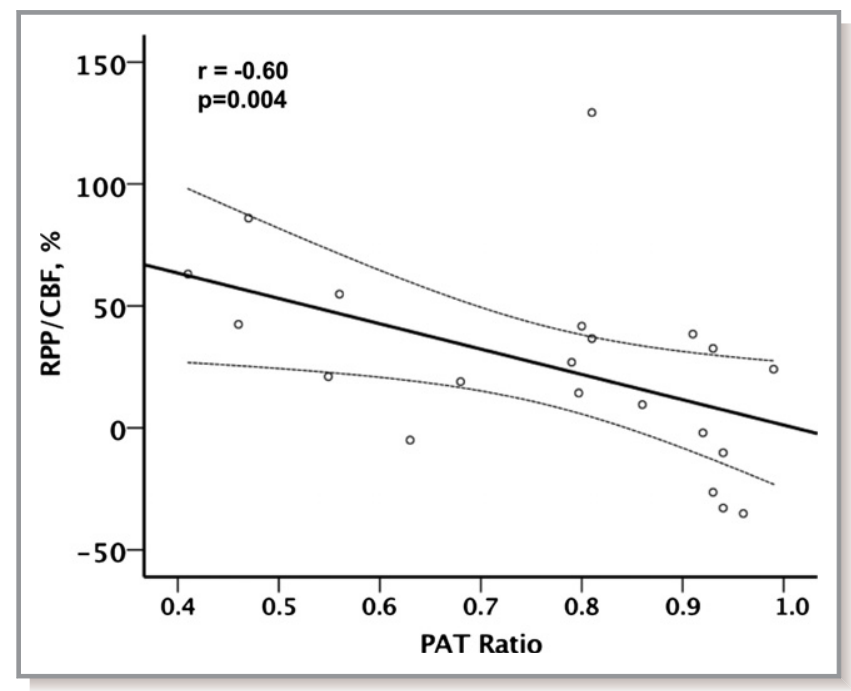

Figure 5. Relationship between mental stress-induced digital microvascular response, measured as the peripheral arterial tonometry (PAT) ratio, and the coronary microvascular vasomotor response, measured as the coronary blood flow (CBF) response adjusted for the rate-pressure product (RPP). The solid line represents the line of best fit, and the dashed lines represent the $95 \%$ confidence interval. function had reduced microvascular vasodilation in response to MS, whereas those with more preserved endothelial function had greater vasodilation with MS. However, we did not observe a clear relationship between coronary epicardial endothelial function and the epicardial responses to MS.

Second, there was a strong relationship between the magnitude of coronary microvascular vasodilation, adjusted for myocardial oxygen demand, and the digital peripheral microvascular response during MS, suggesting that similar factors influence coronary and peripheral microvascular reactivity during stress. Taken together, our study shows, for the first time that the health of the coronary microvascular endothelium, at least partly determines coronary vasodilation during psychological stress, and the latter is reflected in the peripheral microvascular vasomotor responses during MS. These findings illustrate potential mechanisms in the pathogenesis of MSIMI that occurs frequently in patients with CAD and is associated with poor outcomes., ${ }^{1,2,18,19}$ We have previously shown that lower digital microvascular reactivity is associated with MSIMI. ${ }^{4,13,14}$ In conclusion, this study shows that the health of the endothelium, but not the endotheliumindependent pathways, modulates coronary and peripheral microvascular reactivity, and therefore blood flow delivery during MS.

We and others have previously shown that epicardial segments of coronary arteries in individuals free of atherosclerosis tend to vasodilate during MS, but in those with CAD, even angiographically smooth segments do not vasodilate, whereas segments with angiographic atherosclerosis tend to vasoconstrict. ${ }^{5,9-11}$ Kop et al further showed that nonstenotic atherosclerotic segments vasoconstrict but not segments with significant atherosclerosis. ${ }^{9}$ Two studies that investigated the relationship between coronary epicardial responses during MS and endothelial function showed that segments with epicardial atherosclerosis vasoconstrict, whereas segments without atherosclerosis vasodilate in response to both MS and acetylcholine. ${ }^{10,11}$ In contrast to these studies we investigated a homogenous population with CAD in whom changes in epicardial arteries without significant $(<20 \%)$ stenosis were studied. Although we found no significant correlation between epicardial responses to MS and acetylcholine, all epicardial segments that constricted with acetylcholine also constricted during MS, whereas the response in those without acetylcholine-mediated constriction was more heterogeneous. It should be emphasized that we selected a single straight unobstructed epicardial segment for measurement in each subject. It is possible that more diseased segments may have shown results similar to those previously reported. Furthermore, with a larger sample size, the correlation could have reached statistical significance.

We and others have previously shown that MS causes greater microvascular vasodilation and thus increase in CBF in 
those without CAD compared to those with $C A D$, even with similar increases in rate-pressure product and thus myocardial oxygen demand. ${ }^{5,9}$ We further showed that despite similar activation of the sympathetic nervous system, measured as coronary norepinephrine turnover with acute MS, patients with CAD had impaired coronary microvascular vasodilation compared to those without CAD. ${ }^{5}$ Thus, MS-induced sympathetic nervous system activation increases myocardial oxygen demand and stimulates $\alpha$-adrenergic receptor-mediated coronary constriction. In the presence of normal vascular endothelial function, this vasoconstriction is countered by shear-mediated release of nitric oxide and other endotheliumdependent vasodilators. With endothelial dysfunction, the adrenergic receptor-mediated constriction supervenes, and the resulting coronary vasoconstriction limits appropriate $\mathrm{CBF}$ increase, potentially resulting in MSIMI. A novel finding of this study is demonstration of the critical relationship between coronary microvascular endothelial function and the vasodilatory response to MS. Regardless of the underlying atherosclerosis burden, endothelial function, and not endothelium-independent responses, modulates the coronary microvascular dilator response to MS.

Endothelial dysfunction is a precursor for the development and progression of CAD, and both epicardial and microvascular responses to acetylcholine are predictive of future risk of adverse cardiovascular outcomes. ${ }^{20,21}$ An impaired response to acetylcholine is indicative of reduced endothelial production of nitric oxide and/or other endothelium-dependent vasodilators such as endothelium-dependent hyperpolarizing factor. ${ }^{22,23}$ Our current findings demonstrating the contribution of coronary endothelial dysfunction to the reduced microvascular dilation during MS, combined with the observation that MSIMI occurs in some patients with CAD, illustrate that 1 likely mechanism by which endothelial dysfunction contributes to increased cardiovascular risk is by promoting MSIMI.

Another important finding of our study is the similarity in the coronary and peripheral microvascular vasomotor responses during MS, demonstrated as a strong correlation between the digital microvascular vasomotion during MS, measured as the PAT ratio and coronary microvascular vasodilation, measured as demand-adjusted change in CBF. Combined with the previous observation that the PAT ratio during MS is an important and independent predictor of MSIMI, ${ }^{13,24,25}$ our current findings imply that microvascular endothelial function is likely to be a critical determinant of MSIMI and that the digital microvascular reactivity reflects coronary microvascular reactivity during stress. Previous studies have shown that forearm microvascular vasodilation during mental stress is impaired in subjects with abnormal endothelial function, lower nitric oxide bioactivity, and greater endothelin activity. ${ }^{26-30}$

\section{Strength and Limitations}

This is the first study to demonstrate the relationship between microvascular endothelial dysfunction and coronary microvascular responses during MS in patients with $C A D$, and to further demonstrate the similarity between peripheral and coronary microvascular reactivity with stress. Limitations include the lack of information on MSIMI in this cohort. Further studies comparing coronary endothelial function between those with and without MSIMI are needed. Because of the small number of subjects in the study, lack of statistical significance with some tests may have been due to lack of statistical power, and the examination of subgroup differences according to sex and other comorbidities was limited. A larger study would be needed to make such comparisons. It should also be emphasized that the correlation between endothelial dysfunction and MS-induced vasomotion does not imply causality. Studies designed to improve endothelial function and its impact on coronary and peripheral vasomotor responses during MS are needed to establish causality.

\section{Conclusions and Implications}

MSIMI is associated with increased risk of adverse cardiovascular outcomes, but its underlying mechanisms are not well understood. ${ }^{18}$ Herein we demonstrate the important contribution of coronary microvascular endothelial dysfunction to the limitation in vasodilation during MS in patients with CAD. Moreover, we demonstrate that coronary and peripheral microvascular responses during MS are similar. Whether improvement of endothelial dysfunction with angiotensin antagonists, statins, and other agents will improve coronary and peripheral responses to MS and improve MSIMI needs to be examined.

\section{Sources of Funding}

Dr Vaccarino, Dr Quyyumi, Dr Bremner, Dr Shah, Dr Samady, and $\mathrm{Dr}$ Sheps report research support from NIH. This work was supported by the NIH (P01 HL101398, P20HL11345101, P01HL086773-06A1, R01 HL109413, R01HL10941302S1, UL1TR000454, KL2TR000455, K24HL077506, and $\mathrm{K} 24 \mathrm{MH} 076955)$. The sponsors of this study had no role in the design and conduct of the study; collection, management, analysis, and interpretation of the data or in the preparation, review, or approval of the article.

\section{Disclosures}

None. 


\section{References}

1. Vaccarino V. Mental stress-induced myocardial ischemia. In: Baune TB, Tully JP, eds. Cardiovascular Diseases and Depression: Treatment and Prevention in Psychocardiology. Cham: Springer International Publishing; 2016:105-121.

2. Burg MM, Soufer R. Psychological stress and induced ischemic syndromes. Curr Cardiovasc Risk Rep. 2014;8:1-6.

3. Jiang W, Babyak M, Krantz DS, Waugh RA, Coleman RE, Hanson MM, Frid DJ, McNulty S, Morris JJ, O'Connor CM, Blumenthal JA. Mental stress-induced myocardial ischemia and cardiac events. JAMA. 1996;275:1651-1656.

4. Hammadah M, Alkhoder A, Al Mheid I, Wilmot K, Isakadze N, Abdulhadi N, Chou D, Obideen M, O'Neal WT, Sullivan S, Tahhan AS, Kelli HM, Ramadan R, Pimple P, Sandesara P, Shah AJ, Ward L, Ko YA, Sun Y, Uphoff I, Pearce B, Garcia EV, Kutner M, Bremner JD, Esteves F, Sheps DS, Raggi P, Vaccarino V, Quyyumi AA. Hemodynamic, catecholamine, vasomotor and vascular responses: determinants of myocardial ischemia during mental stress. Int J Cardiol. 2017;243:47-53.

5. Dakak N, Quyyumi AA, Eisenhofer G, Goldstein DS, Cannon RO III. Sympathetically mediated effects of mental stress on the cardiac microcirculation of patients with coronary artery disease. Am J Cardiol. 1995;76:125130.

6. Nabel EG, Ganz P, Gordon JB, Alexander RW, Selwyn AP. Dilation of normal and constriction of atherosclerotic coronary arteries caused by the cold pressor test. Circulation. 1988;77:43-52.

7. Duncker DJ, Bache RJ. Regulation of coronary blood flow during exercise. Physiol Rev. 2008;88:1009-1086.

8. Lacy CR, Contrada RJ, Robbins ML, Tannenbaum AK, Moreyra AE, Chelton S, Kostis JB. Coronary vasoconstriction induced by mental stress (simulated public speaking). Am J Cardiol. 1995;75:503-505.

9. Kop WJ, Krantz DS, Howell RH, Ferguson MA, Papademetriou V, Lu D, Popma JJ, Quigley JF, Vernalis M, Gottdiener JS. Effects of mental stress on coronary epicardial vasomotion and flow velocity in coronary artery disease: relationship with hemodynamic stress responses. J Am Coll Cardiol. 2001;37:1359-1366.

10. Yeung AC, Vekshtein VI, Krantz DS, Vita JA, Ryan TJ Jr, Ganz P, Selwyn AP. The effect of atherosclerosis on the vasomotor response of coronary arteries to mental stress. N Engl J Med. 1991;325:1551-1556.

11. Boltwood MD, Taylor CB, Burke MB, Grogin H, Giacomini J. Anger report predicts coronary artery vasomotor response to mental stress in atherosclerotic segments. Am J Cardiol. 1993;72:1361-1365.

12. Arrighi JA, Burg M, Cohen IS, Kao AH, Pfau S, Caulin-Glaser T, Zaret BL, Soufer R. Myocardial blood-flow response during mental stress in patients with coronary artery disease. Lancet. 2000;356:310-311.

13. Hassan M, York KM, Li H, Li Q, Lucey DG, Fillingim RB, Sheps DS. Usefulness of peripheral arterial tonometry in the detection of mental stress-induced myocardial ischemia. Clin Cardiol. 2009;32:E1-E6.

14. Ramadan R, Sheps D, Esteves F, Maziar Zafari A, Douglas Bremner J, Vaccarino V, Quyyumi AA. Myocardial ischemia during mental stress: role of coronary artery disease burden and vasomotion. J Am Heart Assoc. 2013;2:e000321. DOI: $10.1161 /$ JAHA. 113.000321.

15. Hammadah M, Al Mheid I, Wilmot K, Ramadan R, Shah AJ, Sun Y, Pearce B, Garcia EV, Kutner M, Bremner JD, Esteves F, Raggi P, Sheps DS, Vaccarino V, Quyyumi AA. The mental stress ischemia prognosis study: objectives, study design, and prevalence of inducible ischemia. Psychosom Med. 2017;79:311317.

16. Prasad A, Zhu J, Halcox JPJ, Waclawiw MA, Epstein SE, Quyyumi AA. Predisposition to atherosclerosis by infections: role of endothelial dysfunction. Circulation. 2002;106:184-190.

17. Dean J, Cruz SD, Mehta PK, Merz CN. Coronary microvascular dysfunction: sex-specific risk, diagnosis, and therapy. Nat Rev Cardiol. 2015;12:406-414.

18. Wei J, Rooks C, Ramadan R, Shah AJ, Bremner JD, Quyyumi AA, Kutner M, Vaccarino V. Meta-analysis of mental stress-induced myocardial ischemia and subsequent cardiac events in patients with coronary artery disease. Am J Cardiol. 2014;114:187-192.

19. Hammadah M, Al Mheid I, Wilmot K, Ramadan R, Alkhoder A, Obideen M, Abdelhadi N, Fang S, Ibeanu I, Pimple P, Mohamed Kelli H, Shah AJ, Pearce B, Sun Y, Garcia EV, Kutner M, Long Q, Ward L, Bremner JD, Esteves F, Raggi P, Sheps D, Vaccarino V, Quyyumi AA. Association between high-sensitivity cardiac troponin levels and myocardial ischemia during mental stress and conventional stress. JACC Cardiovasc Imaging. 2018;11:603-611.

20. Halcox JP, Schenke WH, Zalos G, Mincemoyer R, Prasad A, Waclawiw MA, Nour K, Quyyumi AA. Prognostic value of coronary vascular endothelial dysfunction. Circulation. 2002;106:653-658.

21. Suwaidi JA, Hamasaki S, Higano ST, Nishimura RA, Holmes DR Jr, Lerman A. Long-term follow-up of patients with mild coronary artery disease and endothelial dysfunction. Circulation. 2000;101:948-954.

22. Quyyumi AA, Dakak N, Andrews NP, Husain S, Arora S, Gilligan DM, Panza JA, Cannon RO III. Nitric oxide activity in the human coronary circulation. Impact of risk factors for coronary atherosclerosis. J Clin Invest. 1995;95:1747-1755.

23. Verma S, Buchanan MR, Anderson TJ. Endothelial function testing as a biomarker of vascular disease. Circulation. 2003;108:2054-2059.

24. Burg MM, Graeber B, Vashist A, Collins D, Earley C, Liu J, Lampert R, Soufer R. Noninvasive detection of risk for emotion-provoked myocardial ischemia. Psychosom Med. 2009;71:14-20.

25. Vaccarino V, Wilmot K, Al Mheid I, Ramadan R, Pimple P, Shah AJ, Garcia EV, Nye J, Ward L, Hammadah M, Kutner M, Long Q, Bremner JD, Esteves F, Raggi $\mathrm{P}$, Quyyumi AA. Sex differences in mental stress-induced myocardial ischemia in patients with coronary heart disease. J Am Heart Assoc. 2016;5:e003630. DOI: 10.1161/JAHA.116.003630.

26. Cardillo C, Kilcoyne CM, Quyyumi AA, Cannon RO III, Panza JA. Role of nitric oxide in the vasodilator response to mental stress in normal subjects. Am J Cardiol. 1997;80:1070-1074.

27. Cardillo C, Kilcoyne CM, Quyyumi AA, Cannon RO, Panza JA. Racial differences in nitric oxide-mediated response to mental stress in the forearm circulation. J Am Coll Cardiol. 1997;29:7433-7433 (Supplement A; Abstract).

28. Cardillo C, Kilcoyne CM, Quyyumi AA, Cannon RO, Panza JA. Abnormal nitric oxide-dependent forearm vasodilation to mental stress in patients with essential hypertension. Circulation. 1996;94:2681-2681 (Supplement S; Abstract).

29. Cardillo C, Kilcoyne CM, Cannon RO III, Panza JA. Impairment of the nitric oxide-mediated vasodilator response to mental stress in hypertensive but not in hypercholesterolemic patients. J Am Coll Cardiol. 1998;32:1207-1213.

30. Spieker LE, Hurlimann D, Ruschitzka F, Corti R, Enseleit F, Shaw S, Hayoz D, Deanfield JE, Luscher TF, Noll G. Mental stress induces prolonged endothelial dysfunction via endothelin-A receptors. Circulation. 2002;105:2817-2820. 


\section{Supplemental Material}


Table S1. Hemodynamic and intracoronary Doppler measurements during the individual steps of the study protocol.

\begin{tabular}{c|cccccc} 
Step & $\begin{array}{c}\text { HR change } \\
(\%)\end{array}$ & $\begin{array}{c}\text { MAP change } \\
(\%)\end{array}$ & $\begin{array}{c}\text { APV change } \\
(\%)\end{array}$ & $\begin{array}{c}\text { Diameter change } \\
(\%)\end{array}$ & $\begin{array}{c}\text { CBF change } \\
(\%)\end{array}$ & $\begin{array}{c}\text { CVR change } \\
(\%)\end{array}$ \\
\hline $\begin{array}{c}\text { Baseline } \\
\text { A }\end{array}$ & Reference & Reference & Reference & Reference & Reference & Reference \\
Acetylcholine & $-2.9[-7.7,4.1]$ & $-2.4[-11.5,8.0]$ & $55.0[17.5,100.0]$ & $0.1[-10.9,8.2]$ & $38.5[8.1,91.3]$ & $-29.1[-49.0,-3.4]$ \\
Adenosine & $0[-5.3,12.0]$ & $3.5[-17.5,53.5]$ & $193.5[117.6,269.6]$ & $13.4[8.7,19.8]$ & $244.4[165.9,397.9]$ & $-71.6[-79.1,58.8]$ \\
Pre-MS ${ }^{\dagger}$ & Reference & Reference & Reference & Reference & Reference & Reference \\
MS & $11.7[5.9,28.7]$ & $11.9[5.3,21.1]$ & $0[-18.1,28.1]$ & $-5.9[-10.5,-2.6]$ & $-2.6[-13.3,15.7]$ & $12.0[-9.0,18.6]$ \\
$\begin{array}{c}\text { Post-MS } \\
\text { recovery }\end{array}$ & Reference & Reference & Reference & Reference & Reference & Reference \\
$\begin{array}{c}\text { Post-MS } \\
\text { Nitylchoprusside }\end{array}$ & $-3.7[-6.67,4.23]$ & $-4.9[-9.2,3.0]$ & $43.2[14.1,132.2]$ & $1.4[-7.4,7.6]$ & $45.3[16.7,150.4]$ & $-34.9[-56.6,-15.1]$ \\
& $8.1[0,17.2]$ & $-12.4[-22.2,-1.9]$ & $76.3[55.2,119.2]$ & $11.9[7.8,22.3]$ & $97.3[58.2,147.4]$ & $-55.1[-67.2,-47.7]$
\end{tabular}

* Baseline was used as the reference for the steps of acetylcholine and adenosine

+ Pre-Mental Stress (MS) was used as the reference for the step of MS.

‡ Post-MS recovery was used as the reference for the steps of post-MS acetylcholine and nitroprusside.

MAP: Mean arterial pressure. HR: Heart rate. APV: Average peak velocity. CBF: Coronary blood flow. CVR: Coronary vascular resistance. MS: Mental Stress Test. 


\begin{tabular}{|c|c|c|c|c|c|c|}
\hline & & $\begin{array}{c}\text { MAP } \\
(\mathrm{mmHg})\end{array}$ & $\begin{array}{c}\text { HR } \\
\text { (bpm) }\end{array}$ & $\begin{array}{c}\text { APV } \\
(\mathrm{cm} / \mathrm{s})\end{array}$ & $\begin{array}{c}\text { CBF change } \\
(\%)\end{array}$ & $\begin{array}{c}\text { CVR change } \\
(\%)\end{array}$ \\
\hline A) Baseline & 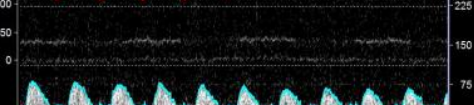 & 122 & 86 & 36 & $\begin{array}{c}\text { Ref } \\
(B, C)\end{array}$ & $\begin{array}{c}\text { Ref } \\
(B, C)\end{array}$ \\
\hline B) Acetylcholine & so 1. & 123 & 82 & 43 & $-4.8 \%$ & $5.9 \%$ \\
\hline C) Adenosine & & 144 & 84 & 80 & $173 \%$ & $-57 \%$ \\
\hline D) Pre-MS & & 121 & 81 & 38 & $\begin{array}{l}\text { Ref } \\
(E)\end{array}$ & $\begin{array}{l}\text { Ref } \\
(E)\end{array}$ \\
\hline E) MS & & 123 & 82 & 26 & $-19 \%$ & $25 \%$ \\
\hline F) Post-MS & & 105 & 70 & 26 & $\begin{array}{l}\text { Ref } \\
\text { (G) }\end{array}$ & $\begin{array}{l}\text { Ref } \\
\text { (G) }\end{array}$ \\
\hline G) Nitroprusside & & 100 & 85 & 57 & $56 \%$ & $-47 \%$ \\
\hline
\end{tabular}

Figure S1. Intracoronary Doppler tracing and respective hemodynamic measurements of a subject during the study protocol. Baseline $(A)$ was the reference for the acetylcholine (B) and adenosine (C). Pre-MS (D) was the reference for MS (E), and post-MS (F) was the reference for nitroprusside $(G)$. Abbreviations: MAP: Mean arterial pressure. HR: Heart rate. BPM: beats per minute. APV: average peak velocity. CBF: Coronary blood flow. CVR: Coronary vascular resistance. MS: Mental stress test. Ref: Reference. 
A) Baseline

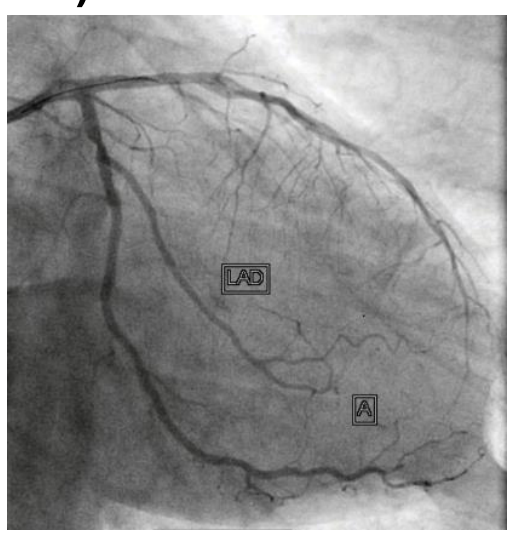

D) Pre-MS

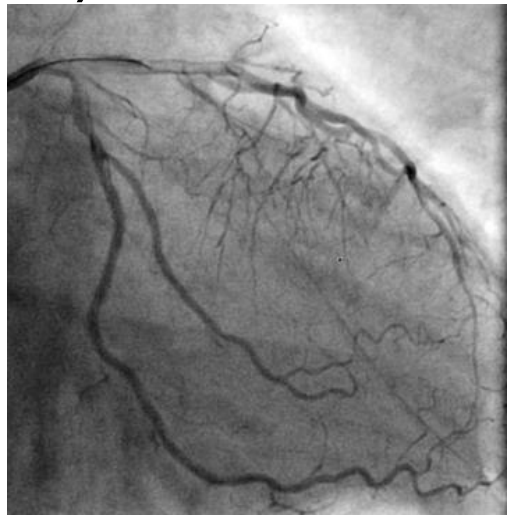

B) Acetylcholine

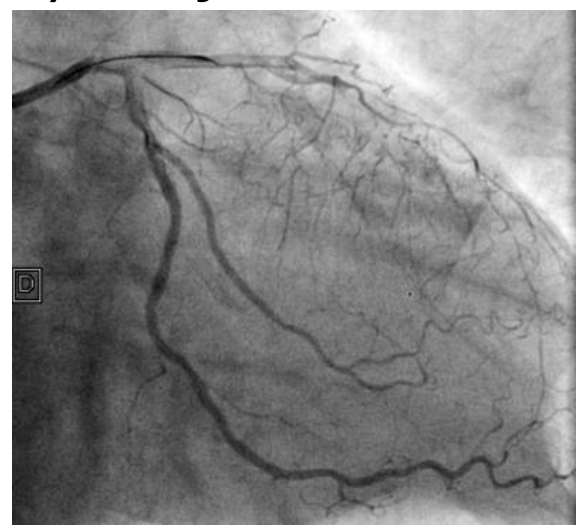

E) During MS

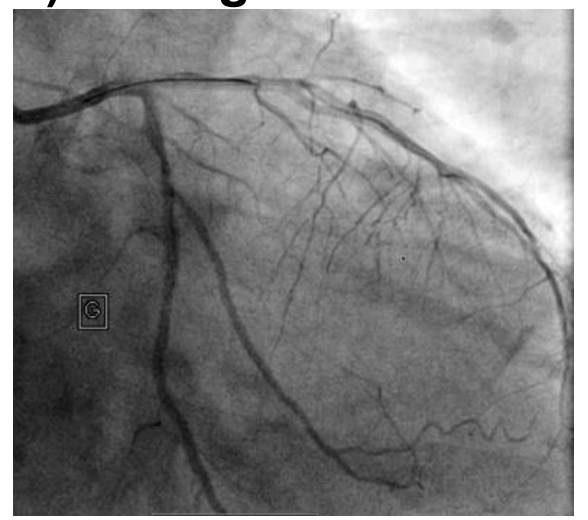

C) Adenosine

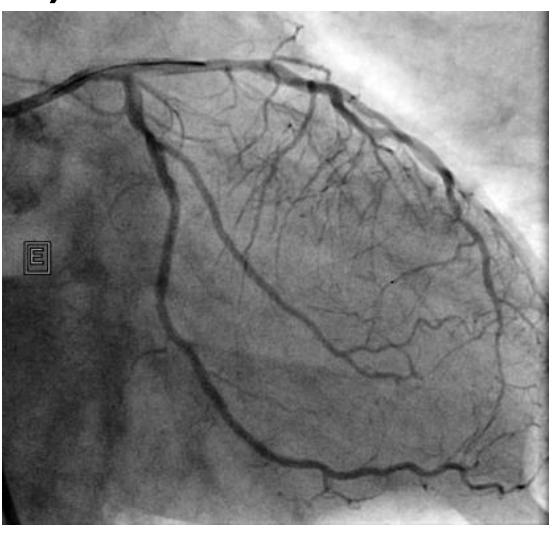

F) Nitroprusside

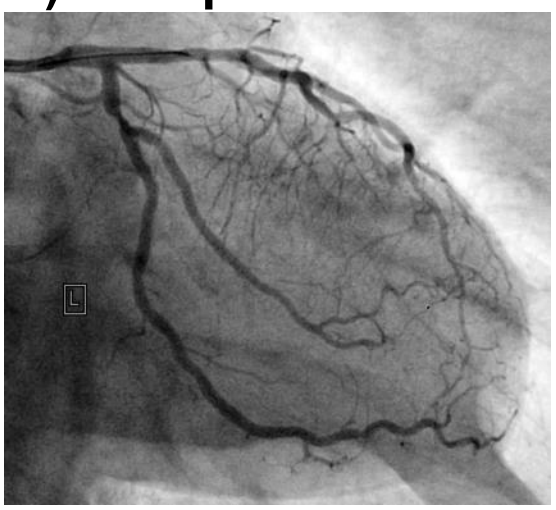

Figure S2. Illustrative example coronary angiography of a subject during the study protocol. Left anterior descending artery was studied for this subject. Abbreviations: MS: Mental stress test. 

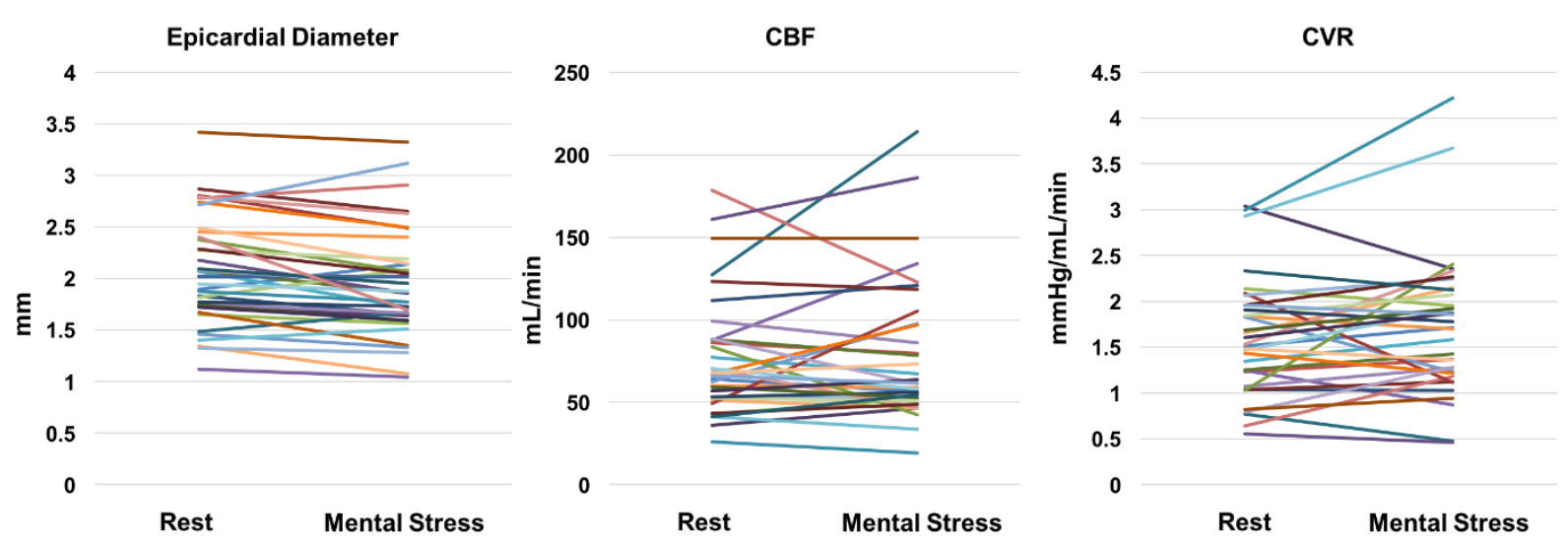

Figure S3. Coronary vascular responses to mental stress. Each line represents one patient. CBF: Coronary blood flow. CVR: coronary vascular resistance. 

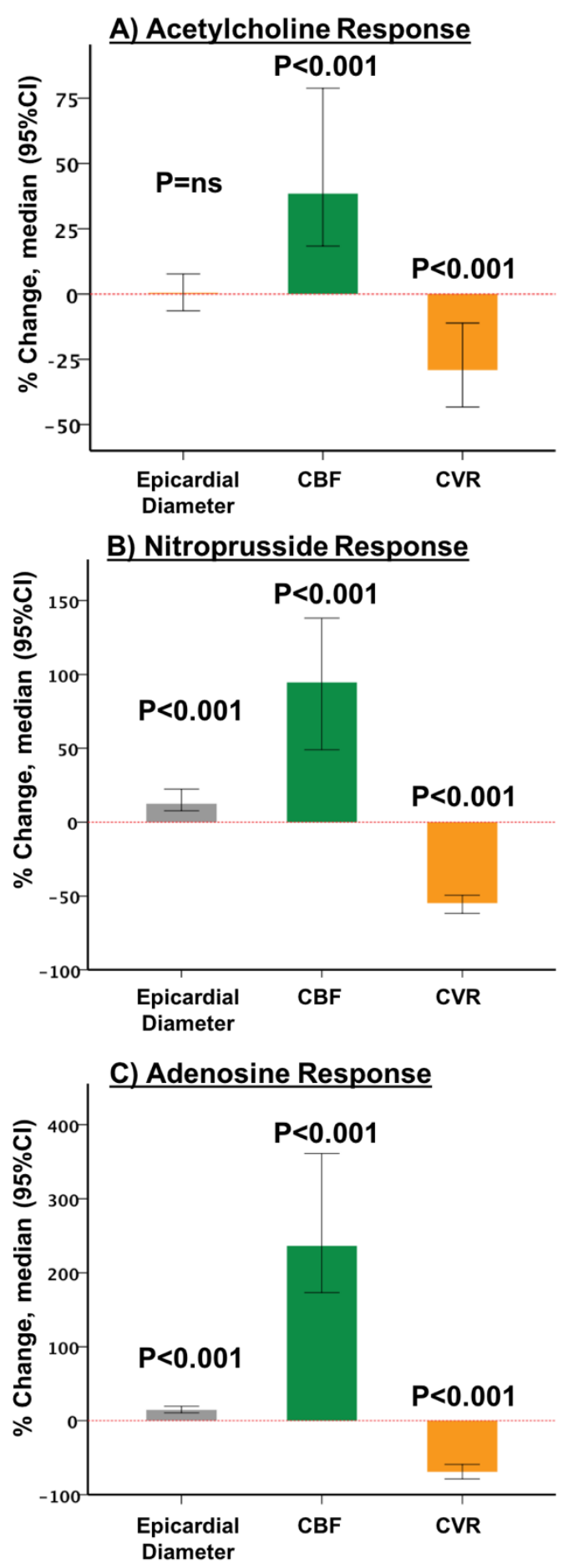

Figure S4. Coronary epicardial and microvascular responses to acetylcholine, nitroprusside, and adenosine. Data is expressed as percent change. Bars represent median change, while error bars represent $95 \% \mathrm{Cl}$. 


\section{A) Acetylcholine Response}
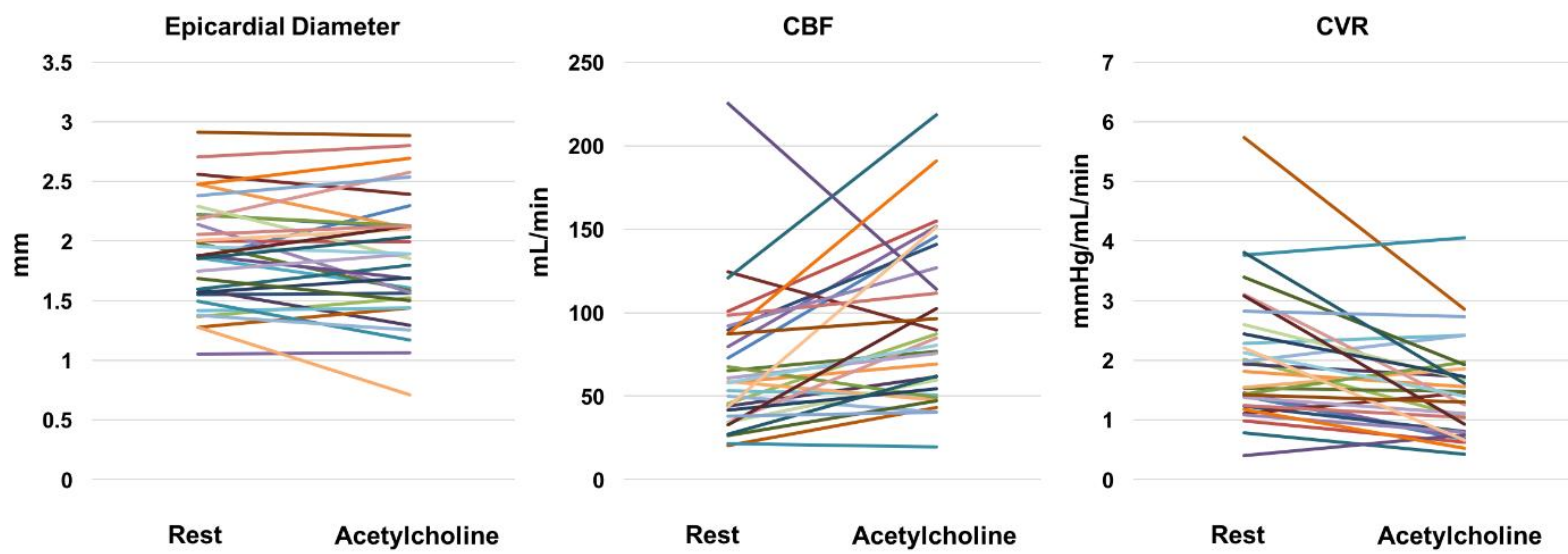

\section{B) Nitroprusside Response}
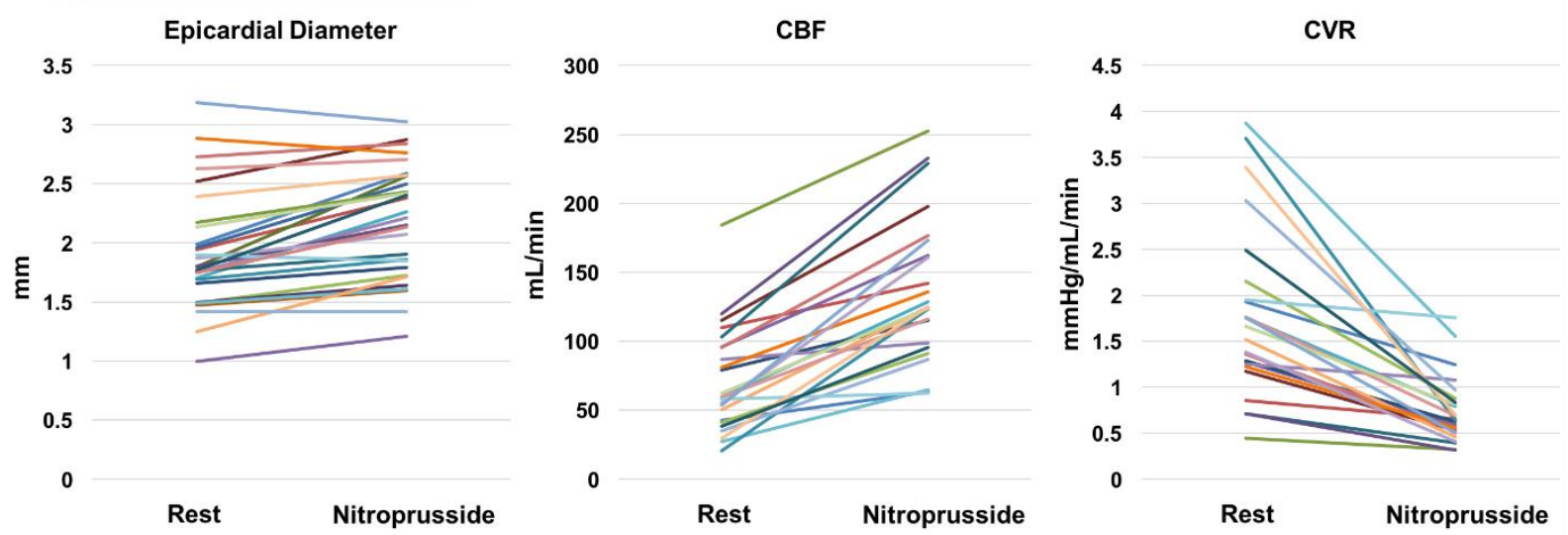

\section{C) Adenosine Response}
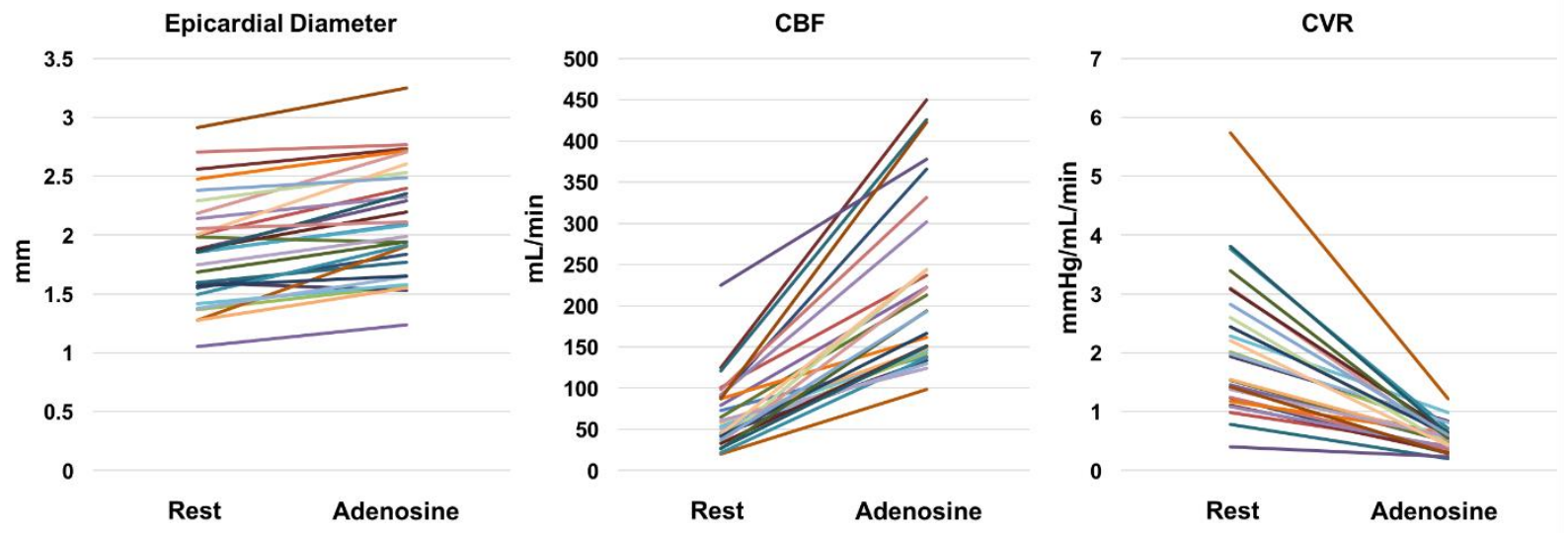

Figure S5. Coronary vascular responses to acetylcholine, nitroprusside, and adenosine. Each line represents one patient. CBF: Coronary blood flow. CVR: coronary vascular resistance. 